\title{
La población extranjera en edad escolar en España: del boom de la inmigración al cambio en el ciclo migratorio'
}

\author{
Alberto Capote y José Antonio Nieto Calmaestra $^{3}$
}

\begin{abstract}
RESUMEN
Durante la década pasada, España fue el segundo destino más importante en los movimientos migratorios internacionales. Se trataba de una inmigración con una notable componente familiar que apostaba por la permanencia en el país. Esto se tradujo en cambios en las aulas de enseñanza, y en el planteamiento de nuevos retos educativos. En este nuevo contexto, las políticas de gestión de la diversidad en los centros educativos han dejado de ser una prioridad. Ahora bien, cabe preguntarse hasta qué punto la pérdida de vigencia de este tipo de acciones es pertinente en un momento en el que ha aumentado el riesgo de exclusión de los colectivos extranjeros en la sociedad española. Las estadísticas oficiales reflejan una doble realidad: el alumnado extranjero ha disminuido, pero las entradas no se han detenido, y se observa una clara tendencia a la permanencia por parte de amplios sectores de las familias inmigrantes en España.
\end{abstract}

Palabras clave: Escuela, crisis económica, inmigración, España, distribución geográfica.

\section{ABSTRACT}

In the past decade Spain was one of the main migratory destinations. It was an immigration of families, these were coming to the country with the intention of staying and it was characterized by uneven geographical distribution. This resulted in changes in education classrooms, raising new educational challenges. However, the economic crisis has led to a change in the migration cycle: decreased inflows and increase outputs. In this new context, policies of attention to diversity are not a priority when they are most needed. Official statistics reflect a dual reality: foreign students has decreased, but inflows have not stopped, a sign of the permanence of many immigrant families in Spain.

Keywords: School, economic crisis, immigration, Spain, geographical distribution. 
En el momento actual, el 17,6\% de las personas con nacionalidad extranjera en España son menores de edad (Instituto Nacional de Estadística-INE: Padrón de habitantes, 1 de enero 2016). Se incluyen en dicho colectivo: niños venidos con sus padres, menores llegados por medio de la reagrupación familiar, menores no acompañados, e hijos de padres extranjeros, que han nacido en territorio nacional. La etapa de mayor afluencia inmigratoria a España, durante la pasada década, conllevó notables cambios en las aulas de enseñanza españolas planteándose en ellas nuevos retos educativos, en un momento en el que se estaban reduciendo las cohortes de alumnado de nacionalidad española como consecuencia del significativo descenso de la natalidad que España vivía desde los noventa. Cabe decir que, aunque España no es actualmente de los países europeos con mayores tasas de población extranjera escolarizada, es cierto que, en poco tiempo, la presencia foránea en las aulas ha pasado a situarse próxima a la media europea (Rahona López y Morales Sequera, 2013), rasgo al que habría que añadir la gran diversidad de orígenes geográficos de este alumnado.

Como es sabido, España en la última década fue el segundo destino más numeroso en cuanto a movimientos migratorios, pero la crisis económica, iniciada en 2008 , ha supuesto un cambio en el ciclo migratorio (Reher et al., 2011; Arango et al., 2014; Torres y Gadea, 2015), pues el número de entradas se ha reducido al mismo tiempo que progresivamente han ido aumentando las salidas, tanto de personas de nacionalidad extranjera como española. Sin duda, uno de los sectores sociales más golpeados por la crisis económica y la destrucción de empleo ha sido el colectivo extranjero (Serrano Martínez y García Marín, 2013; Gil Alonso y Vidal Coso, 2015) que presenta una situación más vulnerable que el resto de la población, por la propia condición de inmigrantes, y lo que ello conlleva: dificultades para renovar el permiso de residencia, falta de apoyo familiar u obstáculos para el acceso a las ayudas sociales (Mahía y De Arce, 2014). En este contexto resulta de interés analizar cuál ha sido la repercusión del cambio en el ciclo migratorio sobre los menores extranjeros y concretamente como esto se ha manifestado en las aulas españolas. Tanto la antigua Ley Orgánica 2/2006, de 3 de mayo, de Educación (LOE) como la Ley Orgánica 8/2013, de 9 de diciembre, para la Mejora de la Calidad Educativa (LOMCE), actualmente en vigor, recogen la obligación de las distintas administraciones educativas de garantizar la escolarización del alumnado que se incorpore al sistema educativo español. Para ello, se empezaron a implantar distintas medidas educativas, las más conocidas las aulas de acogida lingüística que fueron gestionadas desde las distintas comunidades autónomas que componen el estado español. Ahora bien, algunos estudios recientes ponen la alerta en la progresiva reducción de los recursos educativos impuesta por las limitaciones del presupuesto público producida desde el inicio de la crisis. Un reflejo de esta situación ha sido la reducción del profesorado para la atención lingüística y la dificultad para mantener los proyectos de mediación intercultural iniciados (Bouachra et al., 2015; Goenechea Permisan, 2015). Porque no se trata de poner en marcha solo medidas de atención a la acogida del alumnado extranjero orientadas al conocimiento lingüístico, sino de poner en marcha iniciativas que gestionen la diversidad desde un enfoque intercultural que puedan tener un impacto positivo más allá de las aulas. Hemos pasado de un proceso de gestación de la diversidad en la sociedad española a un contexto, especialmente difícil en los últimos años. Como afirman Bueno y Domingo (2016), la limitación de los recursos para las políticas centradas en el asentamiento de la población inmigrante (incluyendo su inserción escolar) se está haciendo en un momento en el que su vulnerabilidad como colectivo es más que evidente.

El objetivo de este artículo es trazar una geografía del alumnado extranjero de enseñanzas no universitarias en España y analizar su evolución desde los años del boom inmigratorio hasta la 
actualidad observando su comportamiento en los años más duros de la crisis económica. Se trata de un momento adecuado para hacer este balance pues el país está en plena fase de cambio de ciclo migratorio tras un periodo de crisis económica con un importante ajuste del déficit público que ha tenido una notable repercusión sobre el sistema educativo español.

El artículo se compone de tres partes: En primer lugar, se examina cuál ha sido la evolución de los menores extranjeros en España, atendiendo a sus principales orígenes geográficos. Durante la pasada década la principal aportación de los inmigrantes a la demografía española fue el rejuvenecimiento de la estructura etaria (Gil Alonso, 2009; Gozálvez Pérez, 2010). En este sentido, la mayor parte de los oriundos de países extra-comunitarios se ajustaba al perfil de personas adultas jóvenes; lo que trajo como consecuencia que la población infantil fuera creciendo tanto a través de la reagrupación familiar como por los nacidos de madre extranjera en territorio español. Se trataba de una inmigración con una notable componente familiar que apostaba por la permanencia en España. Muchos inmigrantes fueron por primera vez padres y madres en España y otros optaron rápidamente por reagrupar a sus hijos desde los países de origen. La cuestión que se plantea en este momento pretende responder a varias preguntas: ¿se ha consolidado la inmigración familiar en España?, ¿se ha reducido la cohorte más joven entre la población extranjera a causa de las migraciones de retorno?, ¿qué ha ocurrido con las entradas?

En segundo lugar, se analiza la evolución de los menores extranjeros en relación a su presencia en las aulas españolas no universitarias, prestando atención a la trayectoria desde el inicio de la crisis económica para ver, en qué medida esta evolución da cuenta del cambio en el ciclo migratorio en España. Debido a la diversidad de orígenes de la población extranjera en España, es necesario atender a la diversidad de situaciones que se puedan dar. No obstante, hay un aspecto común en la inmigración en España independientemente de la procedencia: los padres y madres inmigrantes han considerado la escolarización de sus hijos como uno de los principales frutos del esfuerzo migratorio (Terrén y Carrasco, 2007). Esta motivación ha sido contrastada en otros países con mayor bagaje migratorio como Francia, donde según Vallet y Caille (2000), las familias inmigrantes presentaban mayores aspiraciones para sus hijos que muchas familias francesas con un perfil socioeconómico similar.

La tercera parte está dedicada a describir la distribución geográfica de los escolares extranjeros a escala autonómica y provincial. A mediados de la década pasada, en plena fase del boom inmigratorio en España, Cachón (2004) apuntaba una serie de elementos a la hora de contextualizar el caso español: la rapidez con la que ha tenido lugar la llegada de alumnos extranjeros, la concentración en determinadas regiones, provincias y ciudades; su fuerte presencia en el sistema público de enseñanza, a la par que fue aumentando el número de autóctonos en el privado, y la reducción de la población nativa en las aulas en general. Estos elementos, a tener en cuenta, han podido contribuir a sobrevalorar en exceso la presencia de alumnos de distinta nacionalidad escolarizados en determinadas áreas geográficas españolas. Hay otro aspecto que caracteriza el caso español con respecto a otros países europeos del entorno, así en Alemania o Francia, países con una trayectoria histórica más dilatada en la recepción de alumnado extranjero, se observa que el asentamiento de la población extranjera se ha localizado sobremanera en ámbitos urbanos, particularmente en poblaciones por encima de los 100.000 habitantes (Eurodyce, 2004). La razón es que fueron las grandes ciudades las que necesitaron mayor mano de obra durante las décadas de 1960 y 1970. Algo similar ocurre con la llegada, más reciente, de alumnos extranjeros en países como Chile o Argentina, donde se aprecia un mayor asentamiento en las grandes áreas 
metropolitanas y particularmente en las áreas más empobrecidas donde el alumnado extranjero se encuentra muy concentrado (Beech y Princz, 2012). Sin olvidar los Estados Unidos, donde los grupos que distinguen como minorías étnicas (hispanos y población afroamericana, es decir, no siempre escolares inmigrados) presentan una enorme concentración en los colegios públicos de los grandes centros urbanos, a menudo en colegios con más de un 70\% de inscripciones (Logan et al., 2012).

¿Cuál es la situación en España? Según los informes de la red Eurydice (2004), durante los años del boom inmigratorio, si bien la presencia extranjera en áreas urbanas de gran tamaño era muy destacada, su difusión por la geografía española en entornos semi-urbanos e incluso rurales no era desdeñable. Aquí no podemos olvidar que uno de los sectores de actividad de atracción de mano de obra extranjera fue la agricultura, uno de los principales nichos de empleo para las nacionalidades extracomunitarias como marroquíes o ecuatorianos, con presencia incluso en zonas que presentaban un alto índice de envejecimiento (Teurel, La Rioja, etc.). En este sentido, parece adecuado ver hasta qué punto existe un paralelismo entre la distribución del alumnado extranjero y el de la población inmigrante e indagar en si existe una influencia de la estructura por edades a escala provincial a la hora de determinar un mayor o menor porcentaje de alumnos de distinta nacionalidad.

Por todo ello, apuntar la perspectiva geográfica y las diferencias territoriales observables debe servir para hacer reflexionar sobre la heterogeneidad de las políticas y programas de atención a la diversidad puestos en marcha en un estado, como el español, donde las competencias educativas están, en gran medida, descentralizadas.

\section{Metodología y fuentes. Las controversias del universo de estudio}

Para abordar los objetivos anteriores hemos utilizado varias fuentes. Por una parte, el Padrón de habitantes, que se realiza con una periodicidad anual, y las Estadísticas de Migraciones del Instituto Nacional de Estadística (INE), que proporcionan una aproximación sobre los flujos migratorios de España, tanto de los que se producen hacia o desde el extranjero, como los tienen lugar a nivel interno entre los distintos territorios que conforman el estado español. Éstas se publican desde 2008 y disponemos de datos desde 2008 a 2014.

Por otra parte, están las estadísticas sobre alumnado extranjero en la enseñanza no universitaria en España, publicadas por el Ministerio de Educación, Cultura y Deporte del Gobierno de España. En el momento de la realización de este artículo se podía acceder a los datos correspondientes a los cursos escolares entre 1999-2000 y 2013-2014. Para el año 2014-2015 los datos eran aún provisionales, por lo que los hemos descartado en esta ocasión. La información utilizada es la siguiente: alumnado extranjero por titularidad/financiación del centro y enseñanza a nivel de comunidades autónomas y provincias, con la posibilidad de consultar también en función de grandes conjuntos geográficos de procedencia. La principal dificultad de esta fuente es que apenas ofrece datos desagregados por países, ya que solo recoge procedencias por grandes áreas geográficas. 
Hay una cuestión a considerar a la hora de la explotación estadística de estas fuentes: el criterio que se ha tenido en cuenta a la hora de elegir el universo de estudio. Este aspecto ha planteado controversias en distintas investigaciones: ¿qué variable usar, la nacionalidad o el lugar de nacimiento? El informe PISA, gestionado por la OCDE, hace una doble distinción para definir lo que considera como alumnos extranjeros: de un lado, el grupo de la primera generación, que hace referencia a los niños y niñas que han nacido en el extranjero y han emigrado posteriormente; $y$, de otro, de segunda generación, donde incluyen a los que han nacido en el país de acogida después de haber emigrado los padres. Dentro de esta clasificación, España aparece con un porcentaje bajo entre los países miembros de la OCDE que participan en el estudio en el primer grupo, y más alto en el segundo (OCDE, 2015).

La elección del criterio más adecuado no ha estado exenta de debate. Uno de los más intensos se lleva planteando en Francia desde la década de los noventa del pasado siglo. Felouzis (2003), por ejemplo, en un estudio sobre el alumnado extranjero en Burdeos consideró la nacionalidad como una opción insuficiente. Ahora bien, desde otros enfoques adoptar otra pauta que no sea la nacionalidad es percibido como un riesgo para la estigmatización de estos jóvenes y de efnificación de los problemas sociales, en detrimento de otras variables de tipo socioeconómico (Stavo-Debauge, 2003; Cohen, 2003). También en Quebec encontramos una distinción entre primera y segunda generación en el alumnado extranjero: no solo se perciben como foráneos a los niños y niñas que han emigrado desde otro país, sino también a los nacidos en Quebec pero de padres extranjeros (Provender, 2006). La reflexión sobre posibles riesgos de estigmatización en función de la categoría que definamos también la hayamos en países Iberoamericanos. Domenech (2014) apunta como los escolares de padres oriundos de Bolivia siguen siendo considerados socialmente como bolivianos pese haber adquirido la nacionalidad argentina, lo que, según los progenitores, se puede traducir en una mayor hostilidad hacia ellos. Bravo (2012), para el caso chileno, pone de manifiesto algo similar: la nacionalidad de los padres acaba constituyéndose en un pseudónimo y estos niños son percibidos siempre como extranjeros.

Tanto el Padrón de habitantes, como las Estadísticas sobre Migraciones, dan la posibilidad de elegir a las personas en función de su nacionalidad o en relación al país de nacimiento. En lo que respecta a las estadísticas del alumnado extranjero, tal y como su nombre indica, se hace referencia a menores con una nacionalidad distinta a la española. Por tanto, con el fin de unificar el análisis, en este artículo se ha optado por el criterio de la nacionalidad. En este sentido, hay que tener en cuenta que aquí se incluyen, como se ha dicho, niños y niñas que han llegado a España con la reagrupación familiar y otros que han nacido en territorio español que tienen la nacionalidad de sus padres. ¿En qué medida estos últimos pueden estar sobre-representados en las estadísticas de alumnado extranjero? González Ferrer (2014) estimaba que a mediados del año 2013 había en España cerca medio millón de niños menores de 15 años con nacionalidad extranjera a pesar de haber nacido en España. Así, su contribución a las estadísticas de alumnado extranjero es más que notable. En la gran mayoría se trataba de padres de origen no comunitario (es decir, de un país no perteneciente a la Unión Europea). Además, cabe pensar que puedan estar más sobre-representados en unas nacionalidades que en otras. En efecto, como señalan Pyniol Jiménez y Sánchez Montijano (2014), el proceso de acceso a la ciudadanía en España, además de ser uno de los más negativos de la Unión Europea, se trata de un sistema desigual ya que da una preferencia a unos colectivos sobre otros. Así, los marroquíes y los pakistaníes son los que obtienen mayores trabas y alcanzan un mayor número de negaciones en las demandas de nacionalidad española, lo 
que, según las autoras, los puede, sin duda, disuadir. Por el contrario, se establecen normas de excepción que facilitan el proceso con orígenes geográficos con los que, según define la jurisdicción española, los lazos históricos han sido muy importantes, entre los que se incluyen países iberoamericanos. Hay que recordar también que el alumnado que está en situación de doble nacionalidad con otro país, se considera español.

\section{Los menores extranjeros en España}

El ritmo de crecimiento de la población extranjera durante la pasada década en España fue bastante rápido. La cifra récord de sitúa en el año 2011 con 5.751 .487 personas empadronadas con nacionalidad extranjera. A principios de la década pasada el volumen era tres veces menos. La tasa de extranjería durante este periodo se multiplicó por 6 seis: pasó de 2,2\% en el año 2000 a un 12,6 en 2011. En el momento actual, los datos más recientes apuntan a un descenso: $10,1 \%$ en 2015. Signo de que estamos en el cambio del ciclo migratorio. Pero volviendo a la década anterior, a la par que la población foránea iba en ascenso, iba aumentando también la cohorte de extranjeros menores de 15 años, además a un ritmo bastante similar. Ambas líneas (total de extranjeros y menores de 15 años) dibujan una trayectoria prácticamente idéntica con valores positivos hasta el 2011. Los datos indican, pues, que desde un principio la inmigración que se iban asentando en España tenía una importante dimensión familiar, particularmente la originaria de países extracomunitarios situados en África (Marruecos a la cabeza) o América Latina. En efecto, distintos autores subrayan la importante y compleja componente familiar de la inmigración en España en un intervalo de tiempo muy corto durante los años del boom inmigratorio, particularmente entre aquéllos que vinieron a España por motivos económicos (Requena y Sánchez Domínguez, 2011; González Ferrer, 2008).

Como venimos apuntando, la presencia de menores extranjeros difiere sustancialmente en función de las procedencias geográficas. En el año 2002, el porcentaje mayor lo encontrábamos entre los oriundos de América Latina (22,1\%), a los que seguían los africanos (16,1\%), los asiáticos $(13,8 \%)$ y, por último, los originarios de la Unión Europea (8,8\%). En 2007, justo después del último gran proceso de regularización de inmigrantes en España (en 2005) y antes del estallido de la crisis, los menores están más representados en el colectivo africano $(18,4 \%)$, seguidos de América Latina y Asia con valores similares en torno al 15\%. Los datos más actuales (2015) revelan un aumento de los porcentajes salvo en el caso de los latinoamericanos (10,1\%). Los africanos siguen estando en primera posición: aproximadamente 1 de cada 4 tiene menos de 15 años. Los menores europeos en edad escolar suben ligeramente $(12,4 \%)$ y, lo que más llama la atención, es la subida de los asiáticos hasta un $19,1 \%$.

Las Estadísticas sobre Migraciones a/desde el extranjero nos permiten discernir qué movimientos se han registrado desde el año 2008. Como podemos ver en el Cuadro No 1, hasta el año 2011 el saldo migratorio de los menores extranjeros era positivo, aunque las entradas empiezan a bajar de manera más rápida de lo que lo hacen las salidas. En los tres años siguientes el saldo es negativo: las salidas van creciendo, aunque solo en 2013 lo hacen de manera significativa, mientras que los registros de entrada, aunque por debajo, se mantienen constantes. En 2015, aunque con escaso diferencial, el saldo vuelve a ser positivo. 


\section{Cuadro No 1}

Flujos de entrada/salida y saldo migratorio de las personas menores de 15 años con nacionalidad extranjera

\begin{tabular}{|c|c|c|c|}
\hline Año & Entradas & Salidas & Saldo \\
\hline 2008 & 95.199 & 34.444 & 60.755 \\
\hline 2009 & 65.725 & 46.148 & 19.577 \\
\hline 2010 & 58.155 & 48.793 & 9.362 \\
\hline 2011 & 57.564 & 50.325 & 7.239 \\
\hline 2012 & 47.221 & 55.269 & -8.048 \\
\hline 2013 & 46.041 & 64.342 & -18.301 \\
\hline 2014 & 49.325 & 51.253 & -1.928 \\
\hline 2015 & 57.257 & 46.069 & 11.188 \\
\hline
\end{tabular}

Fuente: INE, Estadísticas de Migraciones.

Con el fin de poner de relieve los contrastes entre las principales áreas de procedencia de la inmigración en España se han elaborado sus pirámides de población en dos momentos: 2007 y 2015 (Figura No 1). Lo primero que llama la atención es la particularidad de los oriundos de la Unión Europea con respecto al resto: se dibuja un mayor equilibrio entre sexos y una estructura más estrecha por la base. No obstante, cabe destacar la notable presencia de adultos jóvenes entre los 25 y los 40 años. En los otros tres conjuntos geográficos el reparto entre sexos es muy desigual, aunque de distinto modo: en el caso de América del Sur, por destacar las mujeres, mientras que entre los africanos y los asiáticos sobresalen los hombres. Estas dos procedencias son las que muestran, además, una mayor presencia de menores en sus estructuras. Es notable especialmente el caso de los africanos pese al desequilibrio entre sexos al que hacíamos alusión. Aquí hay que tener en cuenta, entre otros factores, que las mujeres africanas, junto, aunque en menor medida, con las asiáticas, son las que proporcionan una fecundidad más alta entre la población extranjera (Gózalvez Pérez, 2010; Devolder y Bueno, 2011). Asimismo, los oriundos de África, en esta ocasión, con los sudamericanos, han sido los que mayor peso han tenido en los procesos de reagrupación familiar (Gózalvez Pérez, 2012), hasta los inicios de la crisis económica.

Pero, ¿qué evolución presentan las pirámides de población para estos cuatro conjuntos geográficos? En lo que respecta a los originarios de la Unión Europea, los cambios son muy tímidos, salvo, quizás, la tendencia hacia una estructura más envejecida. En los otros colectivos, sí son más perceptibles. En el grupo de los sudamericanos la variación entre las dos pirámides se resume en una disminución de las cohortes más jóvenes (menores de 15 años) a la par que aumentan los grupos a partir de los 35 años. En el caso de los africanos, este incremento, conforme la edad avanza, es aún más visible, pero, al mismo tiempo, también tiene lugar en la base de la pirámide, particularmente por debajo de los diez años. Algo similar a lo que ocurre en el colectivo asiático, pero con una base piramidal más estrecha. 
Figura No 1

Evolución de la estructura por sexo y edad de los principales colectivos de inmigrantes residentes en España, 2007-2015
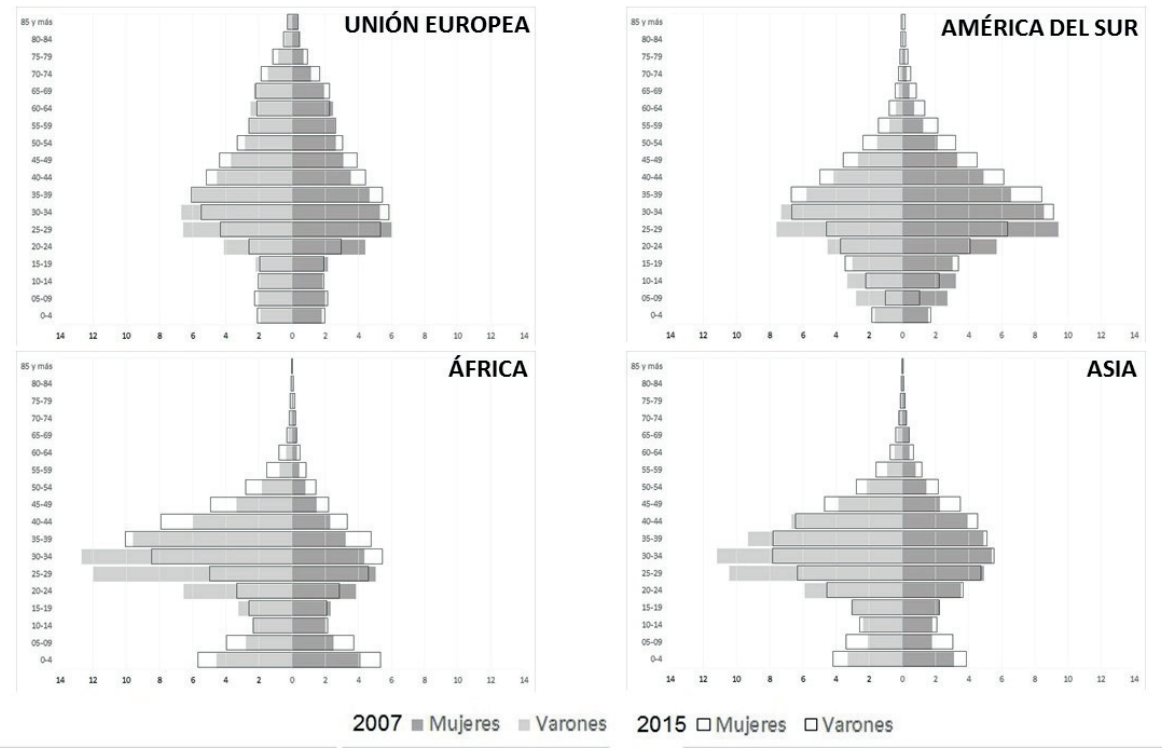

Fuente: Elaboración propia basado en datos de INE, Padrón de habitantes

\section{Evolución del alumnado extranjero en España}

Vistos los datos anteriores, desde el inicio de la pasada década hasta principios de la actual, la evolución del alumnado extranjero en España ha seguido una trayectoria positiva. Entre el curso 1999/2000 (primera fecha de la que tenemos información) y el 2011/2012 (año en el que se alcanzó la cifra más alta hasta ahora) el número de alumnos de nacionalidad extranjera se ha multiplicado por siete. Es solo en los últimos años cuando la cifra ha empezado a descender, aunque no de manera muy pronunciada. El periodo de mayor crecimiento tuvo lugar entre los cursos 1999/2000 y 2003/2004: la cifra subía cada año escolar por encima del $20 \%$ con respecto al curso escolar anterior. El crecimiento se mantiene bastante fuerte hasta el curso 2007/2008, aunque menos (por encima del 10\% de variación interanual porcentual). Es justo a partir del año siguiente cuando el ascenso es más moderado hasta llegar a ser negativo por primera vez en curso 2012/2013. No obstante, el descenso no se puede catalogar como brusco y, como veremos más adelante, no afecta por igual a todas las nacionalidades.

En efecto, la composición del amplio abanico de nacionalidades del alumnado extranjero en España ha sufrido en estos años modificaciones. Si tomamos en consideración el primer año de referencia (1999/2000), dos áreas geográficas suponían casi la mitad del stock de procedencias: América del Sur (19,7\%) y África (29,7\%). Al añadirle el alumnado procedente de la Unión Europea (18\%), contábamos con casi el 70\%. Poco después, desde el curso 2001/2002, los originarios de América del Sur fueron mayoritarios, aunque han ido perdiendo peso progresivamente. En el cur- 
so $2003 / 2004$ la procedencia latinoamericana llegó a representar el $46,4 \%$ del alumnado extranjero. Diez años más tarde este porcentaje desciende hasta un $26,8 \%$, debido sobre todo a que ganan peso los alumnos con nacionalidad africana, asiática y los de algún país de la Unión Europea. En lo que respecta a estos últimos, hay que tener en cuenta que a partir del curso 2007/2008 se integra en esta categoría el alumnado procedente de Rumanía. El análisis en términos absolutos nos revela que el alumnado de América del Sur, aunque ha perdido peso relativo, ha aumentado sobremanera desde principios de la pasada década: entre el curso 1999/2000 y 2011/2012, su cifra se ha multiplicado por 12, mientras que los asiáticos y los africanos lo han hecho por 6 . En lo que respecta a los originarios de la Unión Europea, se han multiplicado por 7, aunque aquí tenemos que tener en cuenta, como se ha dicho, la inclusión de los oriundos de Rumanía que pasaron a formar parte de la Unión en el año 2007.

La observación a partir de las principales nacionalidades revela que, pese a este amplio abanico, también se puede hablar de una importante concentración, la cual se ha ido además subrayando con los años. En el curso 1999/2000 sobresalían claramente los marroquíes con un 23,5\%, seguidos, pero a mucha distancia, por alumnado alemán $(6,4 \%)$ y británico $(6 \%)$. En esa fecha, siete nacionalidades sumaban poco más de la mitad: a las ya citadas habría que sumar las procedencias de Colombia, República Dominicana, Francia y Portugal. En el curso 2011/2012, cuatro nacionalidades rozaban la mitad del alumnado extranjero en las aulas: Marruecos, de nuevo a la cabeza, seguida de Rumanía, Ecuador y Colombia. Reino Unido era la segunda nacionalidad más numerosa, después de la rumana, procedente de un país de la Unión Europea.

Como hemos dicho anteriormente, a partir del curso 2012/2013 empieza a apreciarse, por primera vez, una evolución negativa. No obstante, este descenso no es rotundo ni repentino, ya que en los años anteriores el ritmo era positivo, pero se había ido apaciguando. En la Figura No 2 aparece la evolución del alumnado extranjero desde la fecha de inicio de la crisis económica hasta los datos más actuales por áreas geográficas de nacionalidad. Podemos ver que la bajada se debe principalmente a la caída del alumnado con nacionalidad en algún país de América Latina. Los africanos también bajan, pero solo en el último año y más modestamente. Solo los asiáticos son los que mantienen una trayectoria ascendente.

En efecto, como podemos ver en el Cuadro $N^{\circ} 2$, el alumnado asiático (chino principalmente) presenta durante todo este periodo una evolución positiva. Pero no es el único caso, también los marroquíes en estos años dibujan una trayectoria ascendente sin altibajos. Tanto el alumnado marroquí como el chino, ven multiplicar entre los cursos 2008/2009 y 2013/2014 sus efectivos por 1,6. En una situación contraria se encuentran las nacionalidades sudamericanas, con una trayectoria negativa casi desde el inicio de la crisis. Los casos más llamativos son los de Colombia $y$, sobre todo, Ecuador. El alumnado ecuatoriano se ha reducido aproximadamente a la mitad en estos años. Se trata de la nacionalidad que más ha visto reducir su número. Le siguen Colombia y después Bolivia. También podemos señalar la tendencia negativa del alumnado británico. En lo que respecta a los rumanos, su caso es más particular: en general su línea también es positiva, pero con una bajada en el curso 2009/2010 que vuelve a reproducirse, más levemente, en el último año del que se disponen datos.

A la hora de hacer una lectura de estos datos, no se puede olvidar que el periodo exigido para la concesión de la nacionalidad española por residencia es bastante menor para las personas oriundas de varios países de América del Sur, lo que facilita que desaparezcan más fácilmente de 
Figura No 2

Evolución del alumnado extranjero en España por grandes áreas geográficas de procedencia, desde el inicio de la crisis económica

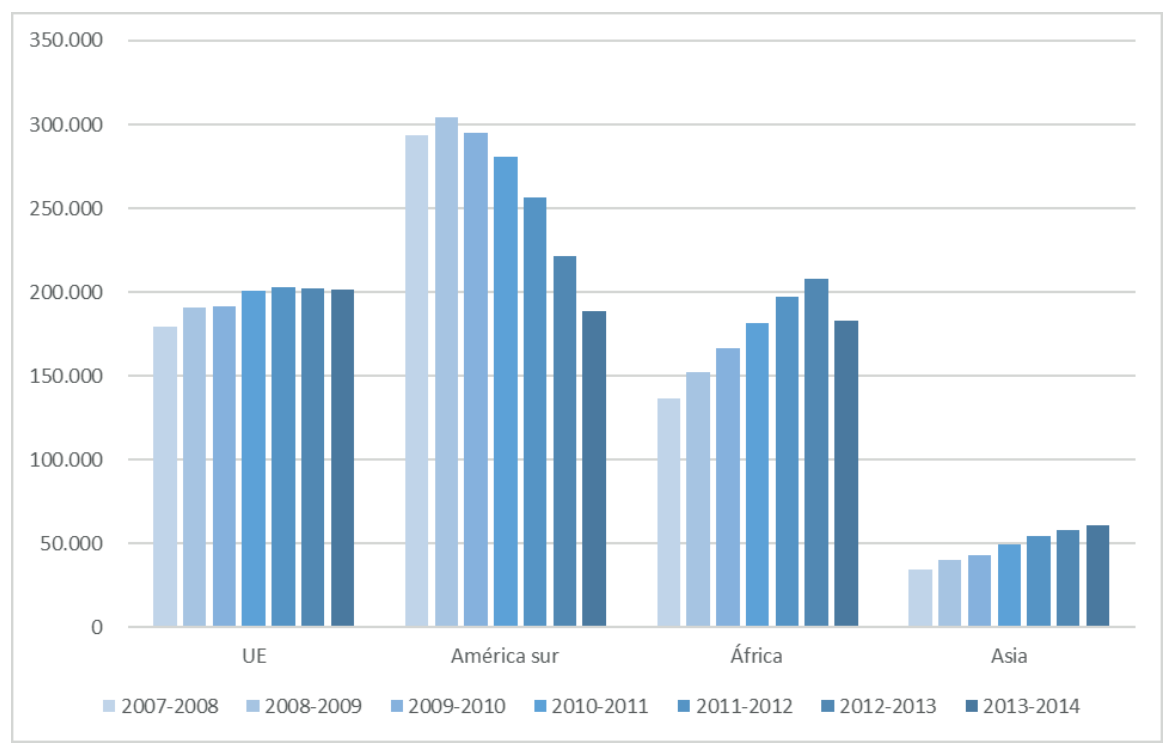

Fuente: Elaboración propia basado en datos del Ministerio de Educación, Cultura y Deporte (Gobierno de España).

\section{Cuadro $\mathrm{N}^{\circ} 2$}

Evolución del alumnado extranjero en España según principales nacionalidades de procedencia desde el inicio de la crisis económica (variación interanual en \%)

\begin{tabular}{|l|r|r|r|r|r|r|}
\hline País & $2008-2009$ & $2009-2010$ & $2010-2011$ & $2011-2012$ & $2012-2013$ & 2013-2014 \\
\hline Marruecos & 10,3 & 7,7 & 8,5 & 8,0 & 5,6 & 3,5 \\
\hline Rumanía & 8,5 & $-1,0$ & 7,5 & 8,3 & 1,3 & $-0,3$ \\
\hline Ecuador & 2,2 & $-4,5$ & $-9,8$ & $-14,7$ & $-20,0$ & $-22,7$ \\
\hline Colombia & 4,7 & $-1,3$ & $-5,1$ & $-10,2$ & $-18,5$ & $-21,2$ \\
\hline Bolivia & $-1,4$ & $-3,7$ & $-3,3$ & $-2,5$ & $-5,2$ & $-7,1$ \\
\hline China & 19,8 & 5,0 & 8,1 & 6,9 & 6,7 & 3,9 \\
\hline Reino Unido & 0,8 & $-8,9$ & $-8,5$ & $-8,8$ & $-8,2$ & $-3,6$ \\
\hline
\end{tabular}

Fuente: Elaboración propia basado en datos del Ministerio de Educación, Cultura y Deporte (Gobierno de España).

las estadísticas de alumnado extranjero. En este sentido, además, hay que tener en cuenta que durante el periodo de la crisis económica se ha acelerado el proceso de acceso a la ciudadanía como mecanismo para hacer frente al deterioro socioeconómico (González Ferrer, 2013; Martínez de Lizarrondo Artola, 2016). Pero, por otra parte, también es cierto que el fenómeno del retorno en 
el contexto de la crisis económica solo se ha manifestado con nitidez en ciertas nacionalidades, entre ellas, Ecuador o Colombia. De ello dan testimonio las estadísticas de solicitudes concedidas en el programa de retorno voluntario: en el caso de los marroquíes las demandas han sido casi inexistentes, en cambio, entre los ecuatorianos y colombianos el número de concesiones registrado es considerable (Parella y Petroff, 2014). Así, el análisis de la evolución del alumnado extranjero durante estos últimos años es otro indicador que revela que el ciclo migratorio se ha visto alterado de desigual modo e intensidad en función de las nacionalidades. Tampoco se puede perder de vista que en los últimos años han seguido llegando niños a España vía reagrupación familiar desde distintos orígenes: el stock se ha reducido porque han aumentado las salidas, pero las entradas se han mantenido, aunque sea en menor proporción, por lo que algunos autores alertan de la necesidad de seguir manteniendo recursos para la atención del alumnado inmigrante recién llegado (García Castaño et al., 2015). Las salidas no nos deben hacer olvidar las entradas. Recordemos, como vimos en el epígrafe anterior, que el saldo migratorio para los menores de 15 años volvía a ser positivo en 2015 después de tres años de dibujarse como negativo.

\section{Distribución territorial del alumnado extranjero}

El alumnado extranjero presenta un reparto muy desigual por el territorio español. Esta distribución ha sufrido cambios desde la pasada década, pero, en líneas generales, ha conservado un mismo patrón espacial. En el curso 1999/2000, cinco comunidades acogían a tres de cada cuatro alumnos extranjeros: en primer lugar, Madrid (28,5\%), seguida, a bastante distancia, por Cataluña, Andalucía, Comunidad Valenciana y Canarias. En el año académico 2006/2007, justo después del último proceso de regularización y en el ecuador de la pasada década en los momentos previos a la crisis, son seis las comunidades que aglutinan a tres de cada cuatro alumnos extranjeros: repiten Madrid, Cataluña, Comunidad Valenciana, Andalucía y Canarias, a las que hay que habría que sumar Murcia. Madrid y Cataluña, ambas con porcentaje similar, albergan al $41,2 \%$, del alumnado foráneo constituyéndose claramente como las principales regiones de acogida. El mismo esquema geográfico lo encontramos en 2011/2012, año que hemos visto que es en el que se alcanza la cifra más alta de alumnado extranjero. En esta ocasión Castilla-La Mancha adelanta a Canarias. Así, en esta primera descripción geográfica por Comunidades Autónomas, vemos que los principales lugares donde se localiza el alumnado extranjero son el litoral mediterráneo (desde Andalucía hasta Cataluña), Madrid como el principal núcleo interior con un efecto irradiación a Castilla-La Mancha que ha ido ganando protagonismo.

Para afinar más en nuestro análisis hemos calculado el coeficiente de localización del alumnado extranjero en cada provincia en relación al total de alumnos/as inscritos/as. Se ha tomado como fecha de referencia el curso 2011/2012. Los datos aparecen representados en la Figura № 3. Como podemos apreciar, las provincias con los valores más altos se localizan en el litoral mediterráneo (Almería, Lleida, Tarragona y Girona) y también, aunque con menos peso, en el cuadrante nororiental, con especial protagonismo de La Rioja y sin olvidar a las Islas Baleares. En la situación opuesta se encuentra toda la franja oeste del país: empezando desde el norte por Asturias y las provincias gallegas, León y Zamora, Badajoz y Cáceres en Extremadura y la mayor parte de Andalucía (Jaén, Córdoba, Cádiz y Sevilla), siendo especialmente bajos los valores. En una situación intermedia se posicionan provincias manchegas (Cuenca y Toledo), Málaga en Andalucía, BarceIona en Cataluña, Burgos y Navarra. 
Figura No 3

Coeficiente de localización del alumnado extranjero en el curso 2011-2012

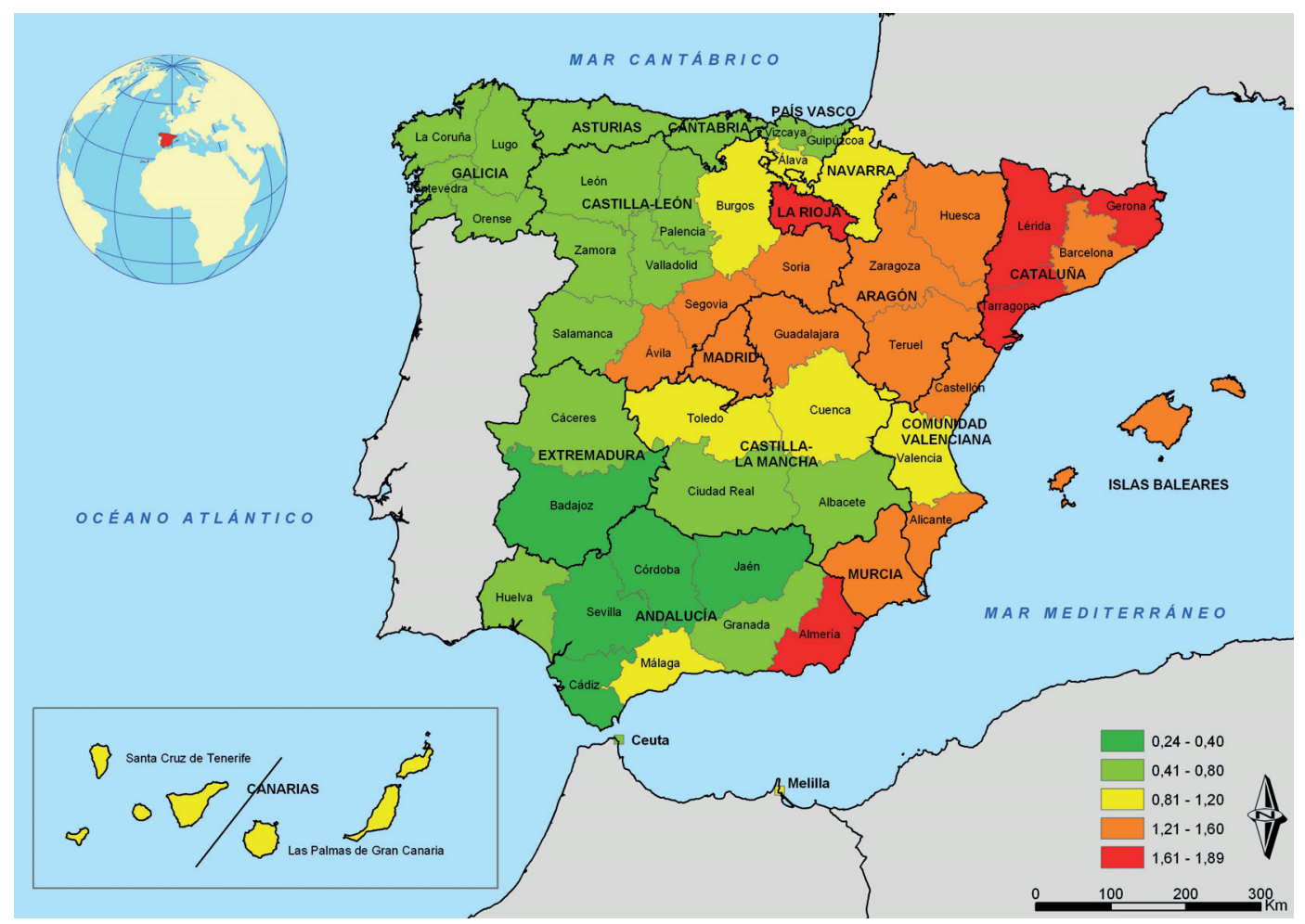

Fuente: Elaboración propia basado en datos del Ministerio de Educación, Cultura y Deporte (Gobierno de España).

El reparto de las procedencias es también desigual entre las provincias españolas (Figura No 4). Desafortunadamente, no podemos conocer la distribución según nacionalidades por países sino simplemente una aproximación por continentes. En las provincias con alta concentración de alumnado extranjero, en el litoral mediterréneo, el origen con más peso es el africano (Almería, Murcia, Tarragona y Girona), con las excepciones de Alicante y, sobre todo, Castellón, donde prevalecen los oriundos de Europa. El alumnado con nacionalidad de procedencia europea también sobresale en provincias como Málaga, Segovia y Cuenca. Las provincias de Madrid y Barcelona presentan una composición de procedencias muy diversa, aunque en este último caso sobresalen más los originarios del continente asiático. La procedencia americana es predominante en un gran número de provincias, por lo general, en aquellas donde hay menos presencia de alumnado extranjero. No obstante, constituyen el grupo más numeroso en Madrid.

Como era de esperar, la mayor parte de las provincias con los porcentajes más altos se caracterizan por ser lugares de acogida de la población inmigrante en España: así, Almería, Baleares, Girona, Lleida, Castellón y Tarragona se encuentran entre las 10 provincias españolas con mayor proporción de población extranjera. 
Figura No 4

Procedencia del alumnado extranjero por continentes, curso 2011/2012

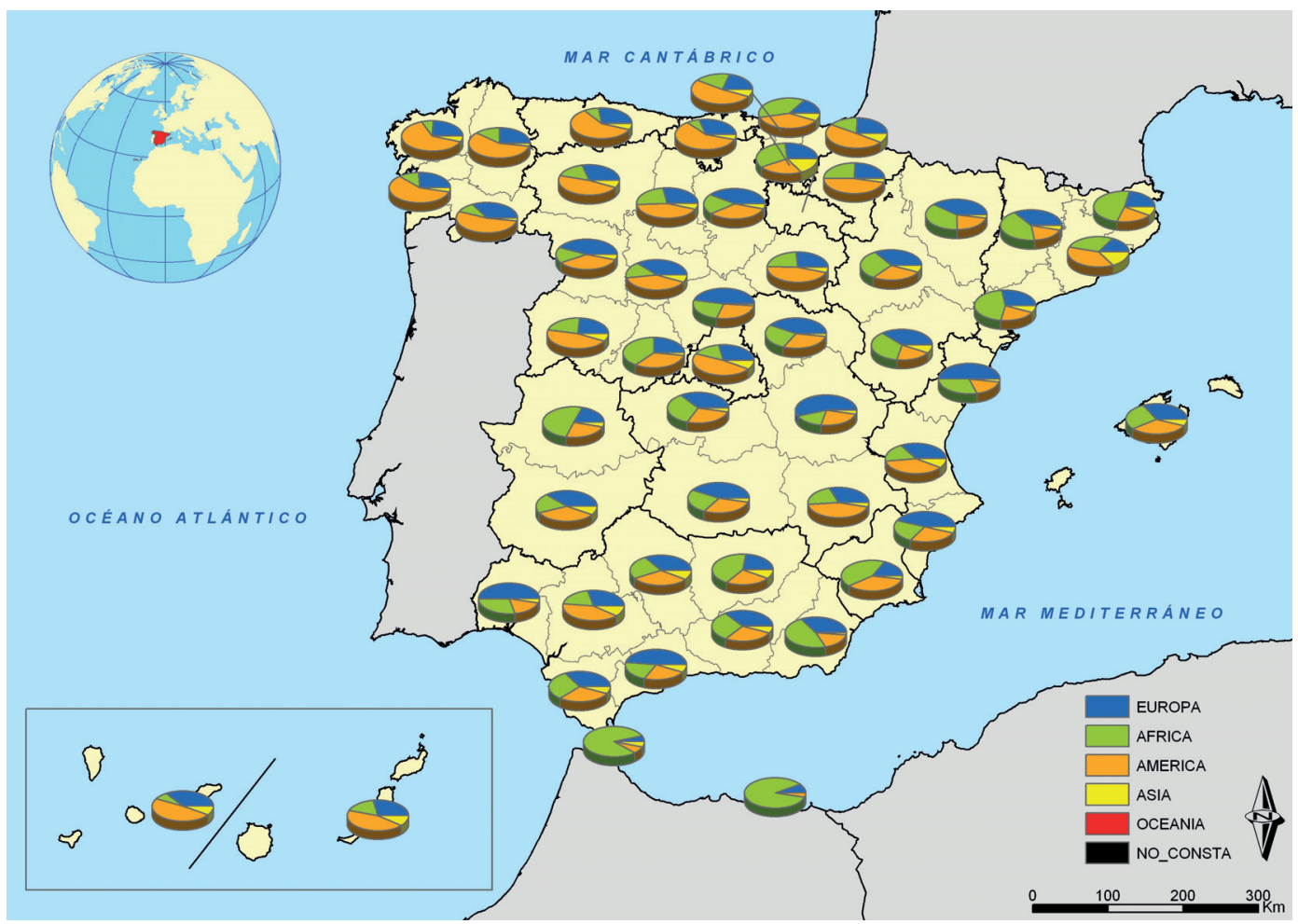

Fuente: Elaboración propia basado en datos en Ministerio de Educación, Cultura y Deporte (Gobierno de España).

Para ver en qué medida se da un solapamiento se ha elaborado la Figura $N^{\circ}$ 5, en la que se relaciona el porcentaje de alumnado extranjero con el de la propia población foránea (los valores altos, medios o bajos de las variables se han establecido haciendo tres conglomerados a partir de las desviaciones típicas de cada variable). Como podemos observar, la mayor parte de las provincias con altos porcentajes de alumnos foráneos (por encima del 15\%) tienen además una alta tasa de extranjería: Almería, Castellón, Tarragona, Girona, Baleares o La Rioja, a las que podríamos sumar Lérida, Cuenca, Madrid y Guadalajara (entre 12-15\%). Málaga ocupa una posición intermedia, aunque con alta presencia de extranjeros, lo que posiblemente se explica porque parte de su stock de inmigración corresponda al de personas en edad avanzada (jubilados europeos) o sin cargas familiares. En cuanto a las provincias del cuadrante nordeste del país (fuera de Cataluña), donde hemos visto que se alcanza también una proporción alta de alumnado extranjero, la incidencia de la inmigración es media. Son los casos, por ejemplo, de Huesca, Zaragoza, Soria, Segovia, Teruel o Ávila.

Así, el factor determinante a la hora de explicar la geografía del alumnado extranjero es la propia distribución de la población inmigrante en España. No obstante, en el mapa se aprecia 
Figura No 5

Relación entre población extranjera y alumnado extranjero, curso 2011-2012

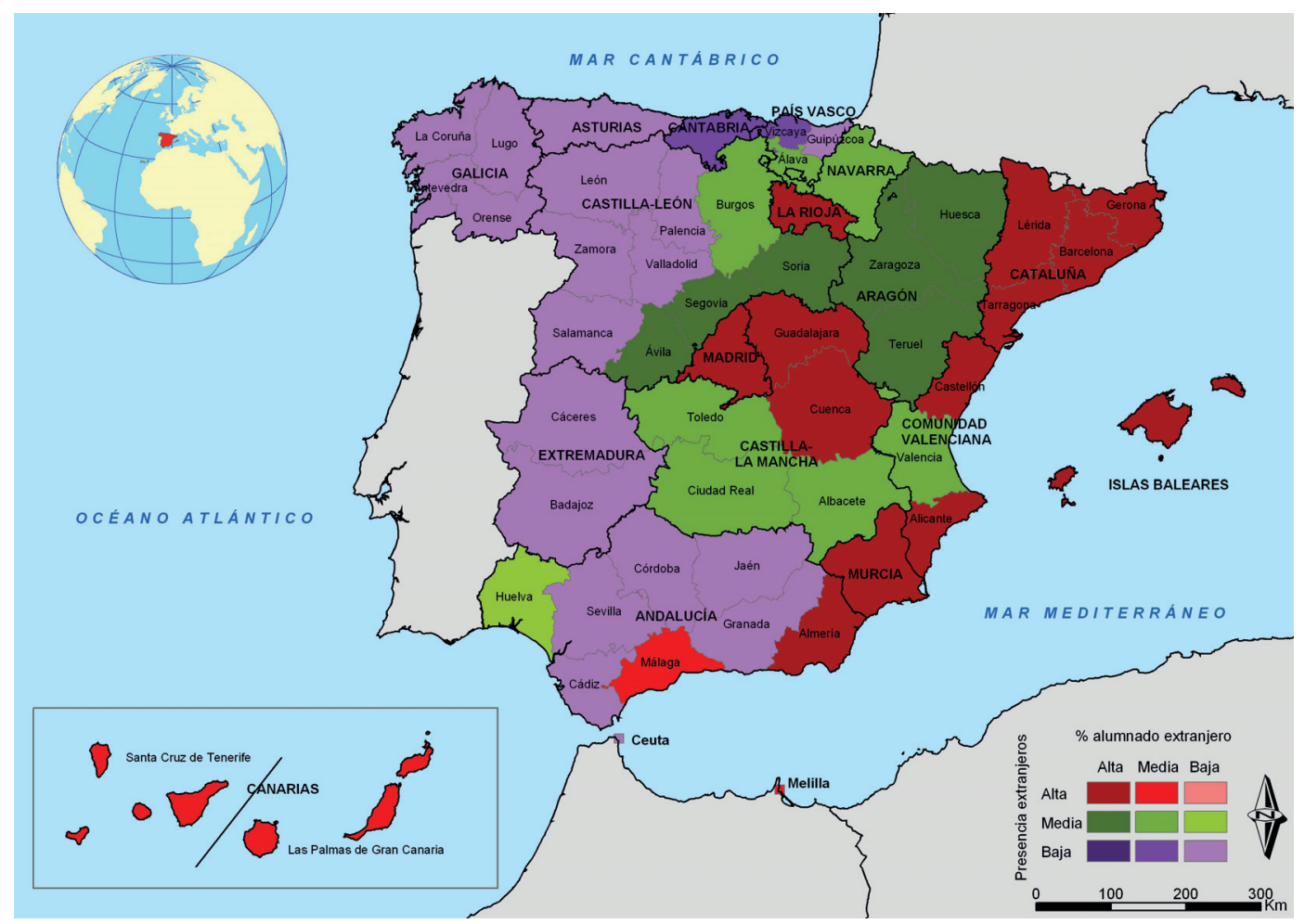

Fuente: Elaboración propia basado en datos de INE, Padrón de habitantes y Ministerio de Educación, Cultura y Deporte (Gobierno de España).

que algunas provincias con alto porcentaje de alumnos de diferente nacionalidad tienen una tasa de extranjería media. Esto nos hace preguntarnos si la estructura de la población puede tener también margen de influencia, aunque este sea más secundario. En un lugar caracterizado por una población mayor y que ha visto reducir el número de niños autóctonos en las aulas, la presencia de alumnado extranjero puede estar sobre-dimensionada. Es la pregunta que nos hemos hecho en provincias como Teruel, Soria o Huesca, por ejemplo, que están en el grupo de las que presentan mayor porcentaje de estudiantes con nacionalidad extranjera y, sin embargo, sus tasas de extranjería están lejos de ser muy altas si las comparamos con otras. En cambio, sí presentan una edad media relativamente alta, lo que nos hace pensar que, al menos, en segundo plano, la estructura de la población juega un papel a la hora de sopesar la presencia de alumnado foráneo.

Para salir de dudas, hemos elaborado dos mapas más: en el primero, se han relacionado el porcentaje de alumnado extranjero escolarizado y la edad media de la población; en el segundo, el cruce se hace entre los extranjeros escolarizados y el total de alumnos inscritos. En lo que res- 
Figura № 6

Relación entre edad media de población y alumnado extranjero, curso 2011-2012

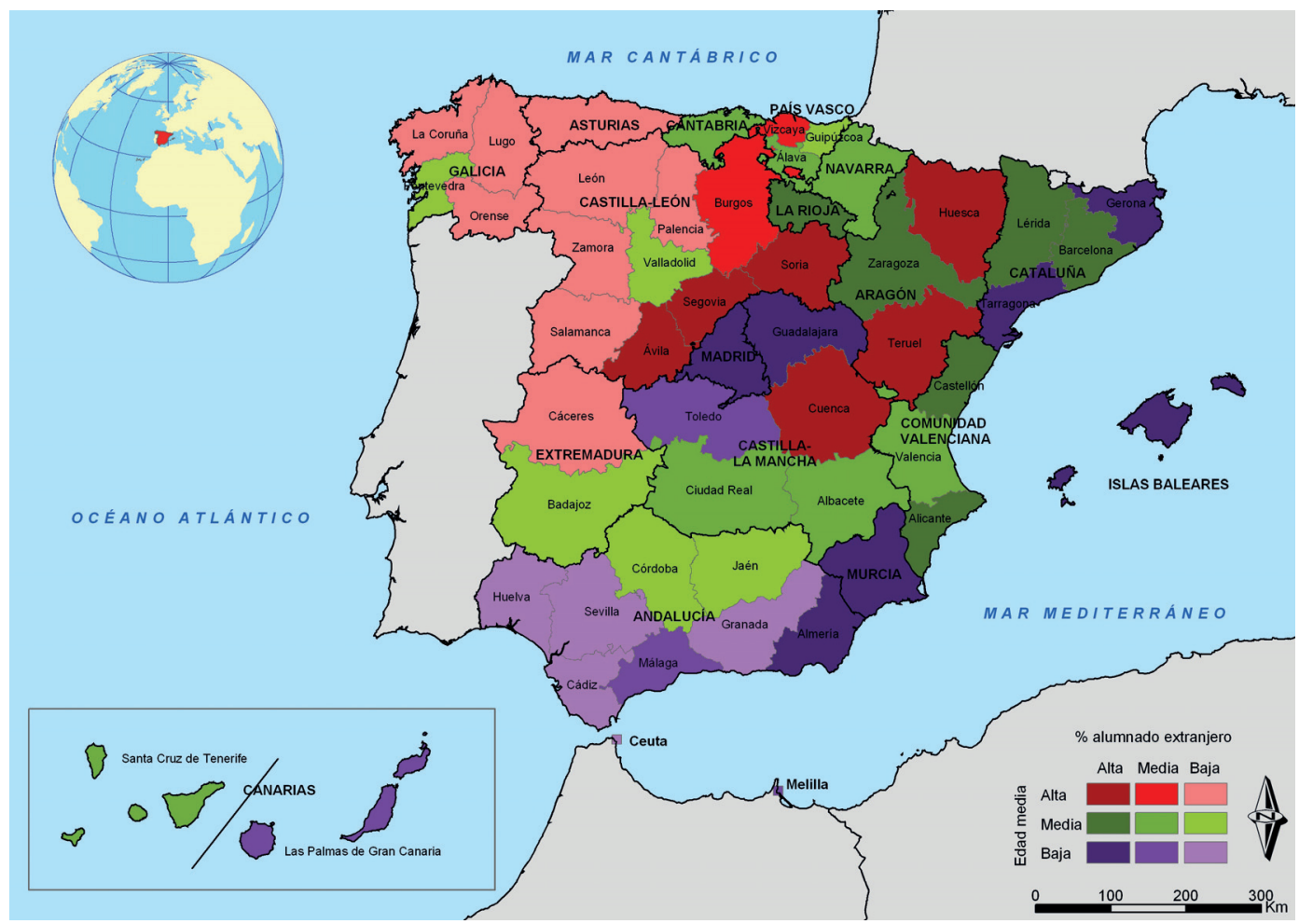

Fuente: Elaboración propia basado en datos de INE, Padrón de habitantes y Ministerio de Educación, Cultura y Deporte (Gobierno de España).

pecta al primer indicador (Figura No 6), se observa que tanto Teruel como Ávila, Soria, Segovia o Huesca presentan una alta incidencia de alumnado extranjero a la par que una edad media muy alta. Algo que no ocurre en Girona, Tarragona, Murcia, Madrid, Baleares o Almería, por ejemplo, que se caracterizan por una población más joven y por un alto porcentaje de alumnado extranjero.

En la lectura de la Figura No 7 vemos como Almería, Murcia, Tarragona y Girona, en el Mediterráneo, y Madrid y Guadalajara en el interior, tienen el perfil de alto porcentaje de alumnos foráneos con una población escolarizada elevada. En Ávila, Soria y Teruel, se da la paradoja de una baja presencia de alumnos a la par que un porcentaje alto de los que tienen nacionalidad extranjera. De este modo, cabe pensar que, aunque solo sea muy ligeramente, la estructura por edad de algunas provincias puede contribuir a sobre-dimensionar la presencia de alumnos escolarizados de distintas nacionalidades. 
Figura No 7

Relación entre población escolarizada y alumnado extranjero, curso 2011/2012

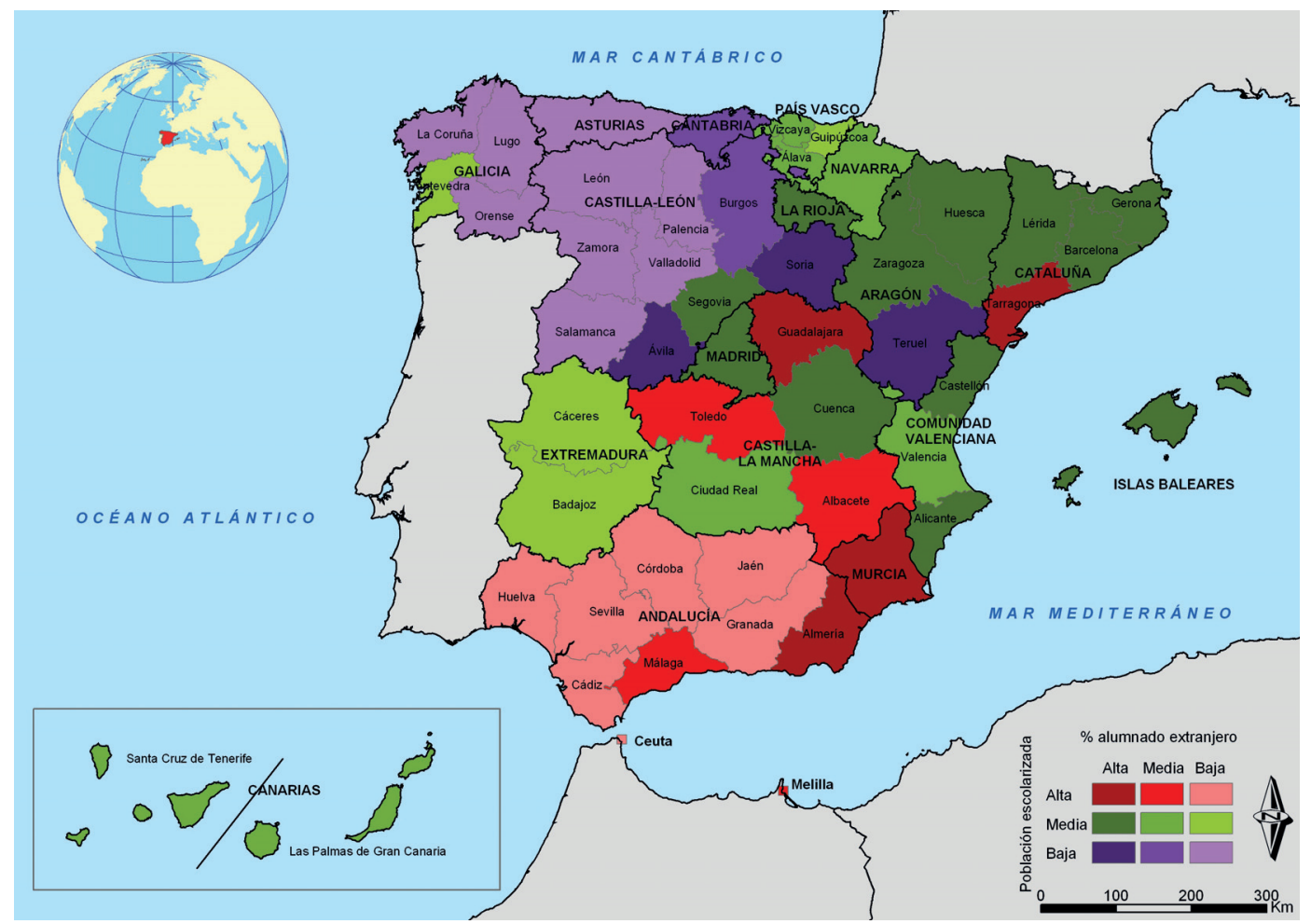

Fuente: Elaboración propia basado en datos de INE, Padrón de habitantes y Ministerio de Educación, Cultura y Deporte (Gobierno de España).

\section{Titularidad del centro educativo}

Los debates en torno a la desigualdad de oportunidades en la educación han girado en torno, generalmente, a las disparidades socioeconómicas de los progenitores (nivel de ingresos, formación, etc). Estas variables influyen, sin duda, en la decisión de los padres a la hora de elegir un centro escolar para los hijos en aquellos países en los que tienen cierto margen de maniobra para poderlo hacer y existe una gama amplia de colegios privados o públicos. Ahora bien, el aumento de la inmigración en muchos países europeos ha implicado la introducción de una nueva variable a tener en cuenta: la del origen geográfico (Jackson et al., 2012). Así, en este último epígrafe, parece oportuno conocer también la distribución del alumnado extranjero en función de la titularidad (privada o pública) del centro. Como se ha dicho en la introducción, en los últimos años se han reducido los recursos destinados a la acogida del alumnado extranjero así como otro tipo de proyectos educativos que fomenten la interculturalidad dentro del marco de una escuela inclusiva. Por este motivo, es importante poner de relieve también cuál es su presencia en el sistema educativo público español. 
El alumnado extranjero se encuentra mayoritariamente inscrito en centros de educación de titularidad pública: en el curso 2011/2012 lo estaba el 82,4\%. Esta sobre-represetanción ha contribuido a que determinados centros tengan una fuerte concentración de alumnado inmigrante por la propia voluntad en la gestión de los dispositivos de acogida, a la par que se denuncia que determinados centros privados, así como concertados, han adoptado un actitud contraria con el establecimiento de barreras para impedir su entrada (Colectivo IOE, 2012). Paralelamente, desde inicios de la pasada década, se ha ido reduciendo el porcentaje de alumnos "autóctonos" en los centros públicos, aunque se vuelve a experimentar una subida en los años de la crisis económica: de un $65,7 \%$ en $2007 / 2008$, se ha pasado a un $67 \%$ en $2012 / 13$. En este aspecto, la situación en España no difiere de la de otros países: tanto con larga trayectoria en la recepciòn de alumnado extranjero, como Canadá (Bakhsaei, 2015) como otros más recientes y con menor presencia extranjera, como Chile (Alvites y Jiménez, 2011; Stefoni et al., 2010) o Argentina (Beech y Princz, 2012). Se constata la existencia en distintos países de un sistema educativo muy fragmentado en el que el alumnado extranjero (particularmente de algunos orígenes geográficos) encuentra muchas dificultades en el acceso a colegios privados y concertados.

Figura No 8

Distribución del alumnado extranjero según titularidad del centro por provincias, curso 2011/2012

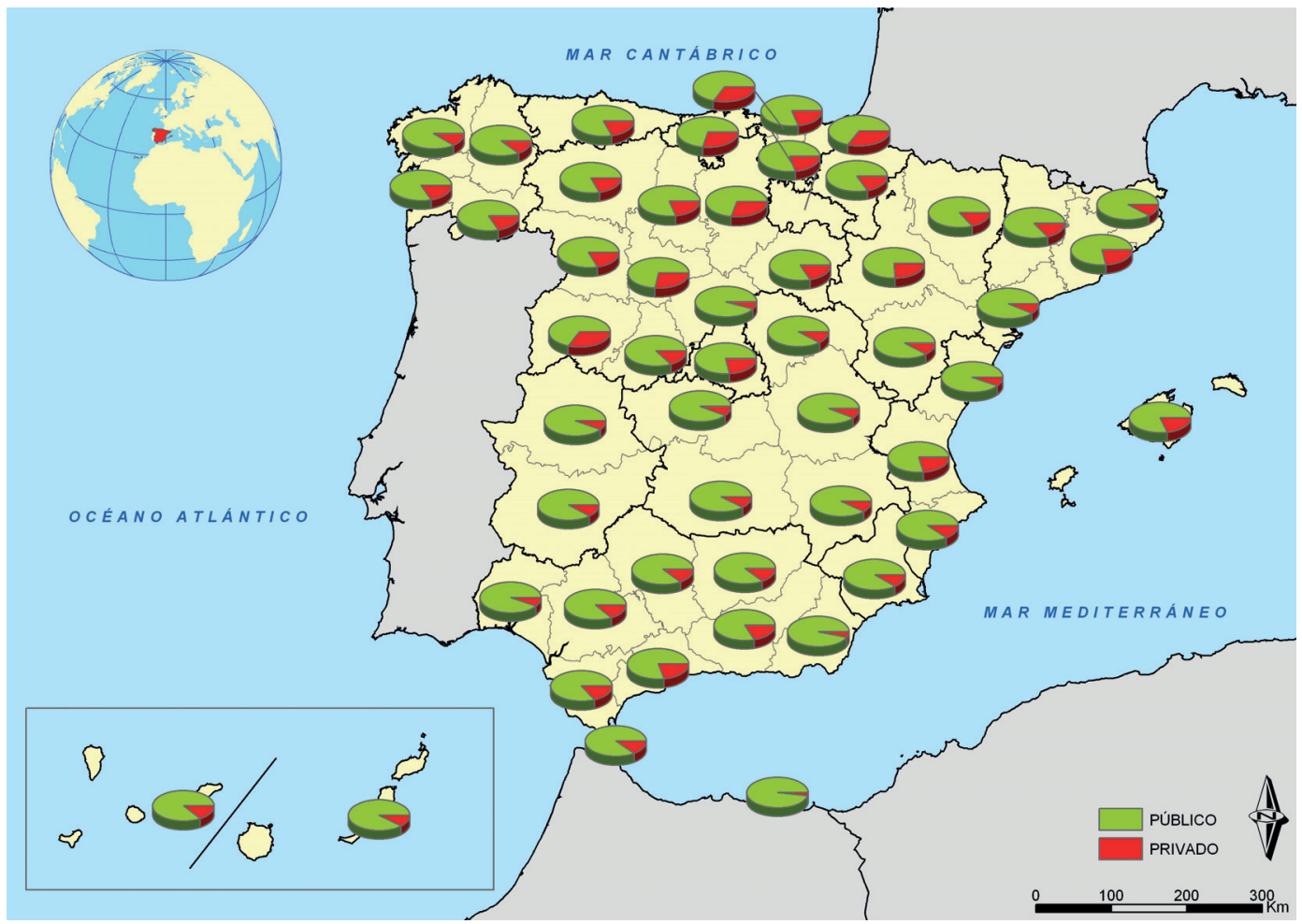

Fuente: Elaboración propia basada en datos de Ministerio de Educación, Cultura y Deporte (Gobierno de España). 
No obstante, volviendo a España, existen diferencias en función de las nacionalidades, aunque de nuevo hay que contentarse con la observación por continentes. El porcentaje más alto de presencia en la escuela pública lo tienen los escolares procedentes del Norte de África $(91,2 \%$, en su mayoría marroquíes) y el más bajo los oriundos de América del Norte $(60,6 \%)$. Los iberoamericanos y europeos se encuentran en una situación intermedia (en torno al 80\%). En lo que respecta a los asiáticos, se trata de tres de cada cuatro.

La primera observación a retener es que en el curso 2011/2012 en todas las provincias, la mayoría del alumnado extranjero se encontraba inscrito en centros de titularidad pública (Figura No 8). Resulta difícil hacer una lectura que capte regularidades geográficas, ya que encontramos provincias dentro de una misma región con porcentajes distintos. Así, las dos provincias con mayor presencia de alumnado extranjero en Andalucía, Málaga y Almería (provincia con el porcentaje más alto en el sistema público), tienen una distribución diferente: la provincia almeriense ocupa la primera posición como el lugar con mayor porcentaje de alumnos foráneos en centros públi$\cos (95 \%)$, mientras en Málaga su presencia desciende hasta el 79,4\%. En Cataluña, Tarragona y Girona presentan porcentajes similares (en torno al 90\%), pero baja en Lleida (84\%) y, sobre todo, en Barcelona (74\%). Las proporciones más altas de inscripciones en centros privados (en torno a una de cada tres) se localizan en provincias con porcentajes de escolares extranjeros bastante bajos en el extremo norte del país: sobre todo, Gipúzkoa, Bizkaia y Salamanca, así como también, Burgos y Cantabria.

\section{Conclusiones}

Si uno de los principales cambios en la sociedad española en lo que va de siglo ha sido la llegada de población de distintos orígenes en un intervalo de tiempo muy corto, éste se ha extrapolado al ámbito educativo. La dimensión familiar ha estado muy presente en la inmigración en España desde el inicio del boom inmigratorio de la pasada década, de manera general en todas las nacionalidades pero particularmente en algunas de ellas (países iberoamericanos, Marruecos, China, etc.). Lo que se tradujo en un ritmo del crecimiento del alumnado extranjero durante la pasada década bastante rápido, situando a España en porcentajes similares a los de otros países europeos con mayor trayectoria como destino de migraciones internacionales (Francia, Alemania, etc). Es solo en los últimos años cuandola reducción del alumnado extranjero en nuestras aulas ha empezado a apreciarse pero no de forma drástica y, además, protagonizada especialmente por algunas nacionalidades. De manera general, todas han visto reducir sus efectivos, pero son los escolares procedentes de América del Sur los que más se han reducido. Queda por ver si en los dos últimos cursos, de los cuales no tenemos información, esta tendencia se ha mantenido o, incluso, ha crecido. Otra pregunta que cabe hacerse de cara a los últimos años, es si van seguir disminuyendo las inscriciones en centros escolares privados, independientemente de la nacionalidad, lo que podría contribuir a mitigar la fuerte concentración en determinados lugares de los alumnos extranjeros.

Por otra parte, en la lectura de los resultados tenemos que tener presente el criterio que el Ministerio de Educación, Cultura y Deporte considera para definir qué es alumnado extranjero. A diferencia de otros países como Canadá o los estudios que se llevan a cabo en la OCDE, prima la nacionalidad en detrimento de criterios como el país de nacimiento o de índole cultural. Así, 
no podemos olvidar por tanto que dentro de la categoria de alumnado extranjero en el caso español se incluye tanto a niños y niñas que han emigrado desde fuera como otros que han nacido en España pero cuyos padres no poseen la nacionalidad española. La adopción de este criterio contribuye a sobre-dimensionar la presencia de alumnos de determiandas nacionalidades en detrimento de otras por el sistema de adquisición de la ciudadanía en España, el cual proporciona un grado desigual de facilidades en función de los orígenes geográficos.

La distribución del alumnado extranjero se ha producido por todo el estado. Es otra de las características del caso español ya que, a diferencia de otros países, la concentración urbana, si bien está presente, lo está en menor medida y su impacto en municipios rurales es considerable. Ahora bien, pese a esta gran difusión, claramente se identifican zonas en las que la concentración es mayor. Sobresalen las provincias del litoral mediterráneo, así como otras adyacentes, a Cataluña por ejemplo. Una posición similar ocupan también Baleares y Madrid. Ahora bien, también cabe destacar su presencia en algunas provincias al nordeste del país y en torno a la comunidad de Madrid: Guadalajara, Soria o Ávila. En líneas generales, la distribución geográfica de los escolares extranjeros guarda paralelismo con el mapa de distribución de la población extranjera en España. Tampoco podemos olvidar que la llegada de alumnado extranjero ha coincidido con una reducción progresiva en el número de escolares españoles inscritos en los centros educativos. Ahora bien, esta evolución demográfica solo ha tenido influencia en determinadas provincias a la hora de aumentar la propia dimensión del alumnado foráneo: es el caso, principalmente, de provincias como Teruel, Ávila, Soria o Segovia. Luego tenemos provincias como Alicante o Málaga, donde la proporción del alumnado extranjero es menor que la de la población extranjera en general, debido a la presencia de personas sin hijos.

El cambio en el ciclo migratorio en España ha reflejado la convivencia de una doble realidad: por una parte, es cierto que el número de efectivos extranjeros ha disminuído en España y muchas personas han emprendido el camino del retorno ante el deterioro de su situación socioeconómica; pero también es cierto que la mayor parte ha permanecido en España intentándose readaptar a las nuevas circunstancias. No de extrañar que pese a que las entradas han disminuido drásticamente, no se han detenido, lo que es señal de un asentamiento familiar consolidado pese a las dificultades sobrevenidas. La diversidad sigue estando presente en la sociedad española, ahora en un contexto más vulnerable que el del boom inmigratorio durante la pasada década. Y esa diversidad se sigue manifestando en las aulas, tanto entre los que se van incorporando como entre los que han encontrado la oportunidad de para asentarse. No se trata pues, de suprimir recursos o considerar innecesarias las políticas o acciones de la gestión de la diversidad desde un enfoque intercultural, sino más bién de adaptarlas a este nuevo contexto que se manifiesta de manera desigual por la geografía española.

\section{Referencias bibliográficas}

ALVITES, L. y JIMÉNEZ, R. Niños y niñas migrantes, desafío pendiente. Innovación educativa en escuela de Santiago de Chile. Synergies, 2011, № 7, p. 121-136. 
ARANGO, J.; MOYA MALAPEIRA, D. y OLIVER ALONSO, J. ¿un año de transición?. En: ARANGO, J.; MOYA MALAPEIRA, D. y OLIVER ALONSO, J. (Directores). Inmigración y emigración: mitos y realidades. Barcelona: CIDOB, 2014, p. 12-24.

BAKHSHAEI, M. La scolarisation des jeunes québécois issus de l'immigration: un diagnostic. Rapport de recherche de la Fondation Lucie et André Chagnon, 2015. Disponible en Internet : http:// www.fondationchagnon.org/media/107917/rapport_recherche_diagnostic_enfants_issus_immigration_version_finale.pdf

BEECH, J. y PRINCZ, P. Migraciones y educación en la Ciudad de Buenos Aires: tensiones políticas, pedagógicas y étnicas. Revista Latinoamericana de Educación Inclusiva, 2012, Vol. 6, № 1, p. 53-71.

BOUACHRA, O.; GARCÍA CASTAÑO, F.J. y OLMOS ALCARAZ, A. Cuando la crisis sirve de excusa. Los recursos escolares para la atención de población de nacionalidad extranjera. En: GARCÍA CASTAÑO, F.J.; MEGÍAS MEGÍAS, A. y ORTEGA TORRES, J. Actas del VIII Congreso sobre Migraciones Internacionales en España. Granada: Instituto Migraciones, Universidad de Granada, 2015, p. 3-22.

BRAVO, R. Inmigrantes en la escuela chilena: ciertas representaciones para ciertas políticas en educación. Revista Latinoamericana de Educación Inclusiva, 2012, Vol. 6, No 1, p. 39-52.

BUENO, X. y DOMINGO, A. La gestión de la interculturalidad en tiempos de crisis: el discurso de los técnicos municipales en Cataluña. Migraciones, 2016, № 30, p. 39-65.

CACHÓN, L. Inmnigrantes jóvenes en España. Sistema educativo y mercado de trabajo. Madrid: Instituto de la Juventud, 2004.

COHEN, A. Las categorías estadísticas de la inmigración: acotaciones a un debate francés. Ería, Revista Cuatrimestral de Geografía, 2003, No 60, p. 5-15.

COLECTIVO IOE. Inserción en la escuela del alumnado inmigrante iberoamericano. Madrid: Organización de Estados Iberoamericanos par la Educación, la Ciencia y la Cultura, 2012.

DEVOLDER, D. y BUENO, X. Interacciones entre fecundidad y migración. Un estudio de las personas nacidas en el extranjero y residentes en Cataluña. Documents d Anàlisi Geogràfica, 2011, No 57-3, p. 469-493.

DOMENECH, E. "Bolivianos" en la "escuela argentina": representaciones acerca de los hijos de inmigrantes bolivianos en una escuela de la periferia argentina. Rehmu, Revista Interdisciplinar da Mobilidade Humana, 2014, No 42, p. 171-188.

EURYDICE EUROPEAN COMMISSION. Integrating Immigrant children into Schools in Europe. Brussels: Eurodyce European Unit, 2004.

FELOUZIS, G. La ségrégation ethnique au collège et ses conséquences. Revue Française de Sociologie, 2003, Vol. 44, No 3, p. 413-447.

GARCÍA CASTAÑO, F.J.; OLMOS ALCARAZ, A. y BOUACHRA OUTMANI, O. Inmigración, crisis y escuela. Migraciones, 2015, No 37, p. 239-263. 
GIL ALONSO, F. Una población en transformación. El impacto de la inmigración extranjera en las estructuras demográficas de la provincia de Barcelona. Treballs de la Societat Catalana de Geografia, 2009, No 66, p. 151-172.

GIL ALONSO, F. y VIDAL COSO, E. Inmigrantes extranjeros en el mercado de trabajo español: ¿más resilientes o más vulnerables al impacto de la crisis. Migraciones, 2015, № 37, p. 97-123.

GOENECHEA PERMISAN, C. Evolución de las ATAL en la provincia de Cádiz. ¿Un recurso a extinguir? En: GARCÍA CASTAÑO, F.J.; MEGÍAS MEGÍAS, A. y ORTEGA TORRES, J. Actas del VIII Congreso sobre Migraciones Internacionales en España. Granada: Instituto Migraciones, Universidad de Granada, 2015, p. 67-78.

GONZÁLEZ FERRER, A. Los niños que nacen en España no son españoles. Eldiario.es, 9 de enero de 2014. Disponible en Internet: http://www.eldiario.es/piedrasdepapel/ninos-nacen-Espana-espanoles_6_215638435.html

GONZÁLEZ FERRER, A. La nueva emigración española. Lo que sabemos y lo que no. Zoom Político, 2013, No 18. Disponible en Internet: http://digital.csic.es/bitstream/10261/93167/1/La\%20nueva\%20emigración\%20española.pdf

GONZÁLEZ FERRER, A. La reagrupación familiar en España: algunas cifras para el debate. En: AJA, E.; ARANGO, J. y OLIVER ALONSO, J. (Directores). La inmigración en la encrucijada. Anuario de la inmigración en España 2007. Barcelona: CIDOB, 2008, p. 120-137.

GOZÁLVEZ PÉREZ, V. Los extranjeros residentes en España: su aportación a la demografía. Investigaciones Geográficas, 2010, № 52, p. 99-136.

GOZÁLVEZ PÉREZ, V. La reagrupación familiar de africanos y latinoamericanos en la España mediterránea. Dinámicas y estructuras sociodemográficas. Estudios Geográficos, 2012, № 273, p. 507-549.

JACKSON, M.; JONSSON, J.O. \& RUDOLPHI; F. Ethnic Inequality in Choice-driven education systems: a longitudinal study of performance and choice in England and Sweden. Sociology of Education, 2012, Vol. 85, No 2, p. 158-178.

LOGAN, J.R.; MINCA, E. \& SINEM, A. The Geography of inequality: why separate means unequal in American Schools. Sociology of Education, 2012, Vol. 93, No 3, p. 287-301.

MAHÍA, R.; y DE ARCE, R. Pobreza de la población extranjera en España. En: ARANGO, J.; MOYA MALAPEIRA, D. y OLIVER ALONSO, J. (Directores). Inmigración y emigración: mitos y realidades. Barcelona: CIDOB, 2014, p. 154-162.

MARTÍNEZ DE LIZARRONDO ARTOLA, A. Naturalizaciones en España: indicador de integración y estrategia frente a la crisis. Migraciones, 2016, № 39, p. 3-37.

ORGANISATION FOR ECONOMIC CO-OPERATION AND DEVELOPMENT (OECD). Immigrant Students at School; Easing the Journey towards Integration. OECD Publishing, 2015. Disponible en Internet: http://www.oecd.org/edu/immigrant-students-at-school-9789264249509-en.htm 
PARELLA, S. y PETROFF, A. Migración de retorno en España: salida de inmigrantes y programas de retorno en un contexto de crisis. En: ARANGO, J.; MOYA MALAPEIRA, D. y OLIVER ALONSO, J. (Directores). Inmigración y emigración: mitos y realidades. Anuario de inmigración de España 2013. Barcelona: CIDOB, 2014, p. 62-87.

PINYOL JIMÉNEZ, G. y SÁNCHEZ MONTIJANO, E. La naturalización en España: una política de claroscuros. En: ARANGO, J.; MOYA MALAPEIRA, D. y OLIVER ALONSO, J. (Directores). Inmigración y emigración: mitos y realidades. Barcelona, CIDOB, 2014, p. 186-209.

PROVENDER, C. Portrait scolaire des élèves issus de l'immigration: de 1994-1995 à 2003-2004. Québec: Ministère de l'Éducation, du Loisir et du Sport, 2006.

RAHONA LÓPEZ, M. y MORALES SEQUERA, S. Educación e inmigración en España: desafíos y oportunidades. Madrid: Organización de Estados Iberoamericanos par la Educación, la Ciencia y la Cultura, 2013.

REHER, D.; REQUENA, M. y SANZ, A. ¿España en la encrucijada? Consideraciones sobre el cambio de ciclo migratorio. Revista Internacional de Sociología, 2011, No 69-1, p. 9-44.

REQUENA, M. y SÁNCHEZ DOMÍNGUEZ, M. Las familias inmigrantes en España. Revista Internacional de Sociología, 2011, No 69, p. 29-104.

SERRANO MATÍNEZ, J.M. y GARCÍA MARÍN, R. Regresión demográfica en España: crisis económica y cambio de ciclo migratorio. Papeles de Población, 2013, No 76, p. 89-128.

STAVO DEBAUGE, J. Prendre position contre les catégories ethniques. Le sens commun constructiviste, une manière de se figurer un danger. In: LABORIER, P. \& TROM, D. (Directores). Historicité de l'action publique. Paris: PUF, 2003, p. 293-327.

STEFONI, C.; ACOSTA, E.; GAYMER, M. y CASAS CORDERO, F. El derecho a la educación de los niños y niñas inmigrantes en Chile. Cuadernos Deusto de Derechos Humanos, 2010, No 58. Disponible en Internet:

http://www.deusto-publicaciones.es/deusto/pdfs/cuadernosdcho/cuadernosdcho58.pdf

TERRÉN, E. y CARRASCO, C. Familia, escuela e inmigración. Migraciones, 2007, No 22, p. 9-46.

TORRES, F. y GADEA, M.E. Un proceso de inserción desestabilizado por la crisis. El nuevo ciclo migratorio y las estrategias de los inmigrantes. En: TORRES, F. y GADEA, M.E. (Coordinadores). Crisis, inmigración y sociedad. Madrid: Talasa Ediciones, 2015, p. 9-35.

VALLET, L.A. \& CAILLE, J.P. La scolarité des enfants d'immigrés. In: VAN ZANTEN, A. (Editor). L'école. l'etat des savoirs. Paris: La Découverte, 2000, p. 293-301. 